\title{
Kinetin affects the level of chloroplast polyamines and transglutaminase activity during senescence of barley leaves
}

\author{
Ewa Sobieszczuk-Nowicka, Przemysław Wieczorek and Jolanta Legocka ${ }^{\bowtie}$ \\ Department of Plant Physiology, Faculty of Biology, Adam Mickiewicz University, Poznań, Poland
}

Received: 09 February, 2009; revised: 25 March, 2009; accepted: 05 May, 2009

available on-line: 12 May, 2009

\begin{abstract}
We analysed the level of polyamines (PAs) bound to thylakoids and the level and activity of thylakoid transglutaminases throughout barley leaf senescence, retarded by kinetin. The level of PAs bound to thylakoids changed in senescing barley leaves: bound putrescine (PU) and spermidine (SD) increased throughout senescence, whereas bound spermine (SM) decreased. Kinetin diminished the increase in thylakoid-bound PU and SD and almost completely abolished the decrease of the bound SM. These data suggest different roles of PU/SD and SM in thylakoid degradation. Immunodetection of transglutaminases (TGase) in thylakoid fraction revealed three bands of 33, 58 and $78 \mathrm{kDa}$. During senescence the intensity of all bands increased and it was correlated with an increase in TGase activity. Kinetin down-regulated the accumulation of the 58- and 78-kDa TGases and the TGase activity. We postulate that formation of covalent bonds between PAs and proteins by TGase is involved in chloroplast senescence. The kinetin-mediated preservation of low TGase levels and activity throughout leaf senescence may represent an important component of the mechanism of kinetin action in the retardation of leaf senescence.
\end{abstract}

Keywords: barley leaves, chloroplasts, kinetin, polyamines, transglutaminases, senescence

\section{INTRODUCTION}

Leaf senescence represents a key developmental phase in the life of plants. It is a period of massive mobilization of nitrogen, carbon and minerals from the mature leaf to other parts of the plant and is a highly regulated, ordered series of events involving cessation of photosynthesis, disintegration of chloroplasts, breakdown of leaf proteins, loss of chlorophyll and removal of amino acids.

Significant chromatin condensation, internucleosomal fragmentation of nuclear DNA (nDNA) and enhanced expression of cysteine proteases in senescing mesophyll prove that leaf senescence is a genetically defined process involving mechanisms of programmed cell death (PCD) (Buchannan-Wollaston, 1997).

Senescence is sensitive to hormonal perturbation, with particular reference to cytokinins. Cytoki- nins prevent chloroplast degradation by retarding both the breakdown of chlorophyll and the decay of the thylakoid system in senescing leaves. Cytokinins lower the activity of the proteolytic enzymes and promote protein synthesis in detached barley leaves senescing in darkness. The delay of senescence by cytokinins is at the transcriptional level as cytokinins, via a signalling pathway, inhibits the transcription of senescence-related genes (Szweykowska \& Schneider, 1994).

Natural polyamines (PAs) are involved in cell growth and cell viability. An increasing body of evidence accumulated over the last five years also hints at their possible role in gene regulation (Kusano et al., 2008). It is then not alltogether surprising that PAs are involved in events inherent to PCD.

PAs associate with numerous molecules by different types of binding. One of these is conjugation to proteins by the action of transglutaminases

\footnotetext{
${ }^{\square}$ Corresponding author: Jolanta Legocka, Department of Plant Physiology, Faculty of Biology, Adam Mickiewicz University, Umultowska 89, 61-614 Poznań, Poland; tel.: (48) 61829 5892; fax: (48) 61829 5887; e-mail: legocka@amu.edu.pl Abbreviations: CP 26, apoprotein of chlorophyll $a / b$ inner antenna complex; LHCPII, light-harvesting chlorophyll $a / b$ complex protein; PAs, polyamines; PCD, programmed cell death, PU, putrescine; SD, spermidine; SM, spermine; TGases, transglutaminases.
} 
(TGases) (R-glutaminyl-peptide:amine ( $\gamma$-glutamyl) transferase, EC 2.3.2.13), a family of enzymes that catalyse the covalent binding of substrates with primary amine groups, like PAs, to the $\gamma$-carboxyamide group of protein endo-glutamine residues (SerafiniFracassini \& Del Duca, 2008). In chloroplasts covalent binding of PAs to proteins might play a significant role in the post-translational modifications of structural proteins or enzymes (Del Duca et al., 1994; Dondini et al., 2003; Sobieszczuk-Nowicka et al., 2007; 2008). TGases are relevant in PCD in animal cells; in fact in several animal cell-lines, the presence and the activity of TGases are considered markers of apoptosis (Griffin \& Verderio, 2000).

An involvement of PAs and TGases in the cascade of reactions leading to senescence/PCD is well documented (reviewed in: Kuehen \& Philips, 2005; Della Mea et al., 2007a; Serafini-Fracassini \& Del Duca, 2008). In contrast to the mammalian PCD (Lorand \& Graham, 2003; Seiler \& Raul, 2005), almost no information is available regarding these factors during senescence/PCD in plants.

With this in mind, we studied the content of bound PAs and the activity of TGases in chloroplast degradation and the effect of retardation of this process by kinetin with the aim of determining whether these factors may represent an important component of the chloroplast degradation process itself, and/or of the mechanism of hormone action.

\section{MATERIAL AND METHODS}

Plant material. Barley (Hordeum vulgare L.) seeds were germinated in moist cellulose in complete darkness for 3 days followed by 7 days of illumination with continuous light of $50 \mu \mathrm{mol} / \mathrm{m}^{2}$ per $s$ (day 0). The primary leaves of the plants were detached, their bases placed in water or $400 \mu \mathrm{M}$ kinetin, and then allowed to undergo senescence in darkness for days 3,5 or 7 at $25^{\circ} \mathrm{C}$. Light limitation initiates the onset of senescence.

Isolation of thylakoid-enriched fraction. Thylakoid membranes from fresh and senescing leaves were isolated according to a modified procedure of Hilditch (1986). Leaves were homogenised in a mortar in a buffer for chloroplast isolation containing $0.4 \mathrm{M}$ sucrose. The homogenate was filtered through 8 layers of gauze and centrifuged for $10 \mathrm{~min}$ at $1500 \times \mathrm{g}$. Chloroplast pellet was suspended in isolation buffer and layered on $3 \mathrm{ml}$ of $65 \%$ sucrose in isolation buffer and centrifuged as above. Chloroplasts were collected from the top of the sucrose layer and centrifuged as previously. Then chloroplasts were osmotically shocked in isolation buffer without sucrose and chloroplast membranes were centrifuged for $15 \mathrm{~min}$ at $12000 \times \mathrm{g}$. The membrane pellet was washed twice and centrifuged as above. The last centrifugation was performed in centrifuge tubes weighted.

PA analysis. PAs bound to thylakoids were determined by thin-layer chromatography (TLC) according to Smith and Best (1977). The pellet of thylakoids was suspended $(100 \mathrm{mg} / \mathrm{ml})$ in $5 \%$ perchloric acid (PCA), and PAs bound to thylakoids were released by hydrolysis in $6 \mathrm{M} \mathrm{HCl}$ for $18 \mathrm{~h}$ at $110^{\circ} \mathrm{C}$. Then PAs were dansylated and separated on TLC plates (silica gel, Merck, Sigma, St. Louis, MO, USA) with cyclohexane and ethyl acetate $(5: 4, \mathrm{v} / \mathrm{v})$. PAs detected by UV lamp were scraped off plates, eluted in $2 \mathrm{ml}$ of ethyl acetate and measured with a spectrofluorimeter (L-2000 Hitachi) using an excitation of $350 \mathrm{~nm}$ and emission at $445 \mathrm{~nm}$.

Colorimetric assay of TGase activity. The biotin-cadaverine incorporation assay was carried out as described by Lilley et al. (1998). Endogenous TGase activity was measured as covalent binding of biotinylated cadaverine to endo-glutamyl residues of $N^{\prime}, N^{\prime}$-dimethylcasein $(\mathrm{DMC})(10 \mathrm{mg} / \mathrm{ml})$ used to precoat the assay microplate. The measurement of enzyme activity was preceded by overnight dialysis (10 mM Tris, pH 8.5 and $1 \mathrm{mM}$ 2-mercaptoethanol) and performed with $5 \mathrm{mM} \mathrm{Ca}^{2+}$; replaced by $1 \mathrm{mM}$ EDTA in the negative control.

Protein blotting. An SDS/PAGE was made according to Laemmli (1970). Proteins (5 and $10 \mu \mathrm{g}$ for CP 26 and TGase, respectively) from isolated thylakoids were dissolved in sample buffer, separated using $12 \%$ polyacrylamide slab gel electrophoresis and transferred onto PVDF membranes using a semi-dry blotting system. Immunoblotting was performed with the use of the ExtrAvidin Peroxidase Staining Kit (Sigma, St. Louis, MO, USA). The optimal dilution of antibodies as estimated by dot-blot was 1:5000 for the anti-TGase sera (RB-060, Ab-4, NeoMarkers $^{\mathrm{TM}}$, Fremont, CA, USA), and 1:3000 for CP 26 (Agrisera, Vannas, Sweden).

Protein assay. Protein was determined using the Bradford method (Bradford, 1976). Bovine serum albumin was used as standard.

Statistical analyses. Each data point represents a mean of three replicates obtained from three independent experiments. The statistical analysis was performed using Standard Method STATISTICA (Stat Soft Inc., Tulsa, OK, USA).

\section{RESULTS AND DISCUSSION}

Since it has been suggested that covalent bonding of PAs with cell structures could be a possible mechanism of PAs involvement in animal cell apoptosis (Seiler \& Raul, 2005) it was interesting to look for PAs bound to thylakoids throughout barley 


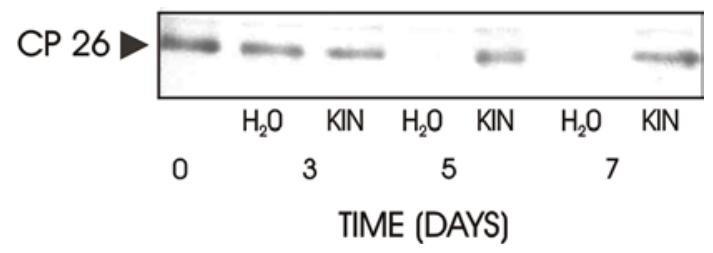

Figure 1. Immunodetection of CP 26 among thylakoid membrane proteins during dark-induced senescence of barley leaves.

The thylakoids were isolated from leaves which were detached (day 0), placed with bases in water (control, $\mathrm{H}_{2} \mathrm{O}$ ) or $400 \mu \mathrm{M}$ kinetin (KIN), and then dark-incubated for days 3, 5 and 7 . Membrane proteins $(5 \mu \mathrm{g})$ were loaded onto a $12 \%$ SDS/polyacrylamide gel and electrophoresed. ExtrAvidin Peroxidase immunostaining was performed with antibodies raised against CP 26. Primary antibody dilution: 1:3000.

leaf senescence. We chose a plant model in which senescence is induced by leaf detachment followed by dark incubation. This treatment induces expression of all the genes that are expressed in age-mediated leaf senescence (Quirino et al., 2000). Exogenously added cytokinin (kinetin) retards the process. This plant model is commonly used to study the senescence process itself and also its cytokinin-retardation (Jackowski, 1996; Legocka \& Zajchert, 1999; Żelisko \& Jackowski, 2004).

Immunodetection of CP 26, apoprotein of the chlorophyll $a / b$ inner antenna complex, used as a marker for the timing of thylakoid degradation, showed in fact that the protein was degraded during the period of analysis ( $0-7$ days) and kinetin retarded its degradation (Fig. 1). The protein was no longer present in control leaves at day 5 of senescence whereas it was still detected in kinetin-treated leaves at day 7 (Fig. 1).

Changes in the level of PAs bound to thylakoids in senescing barley leaves were observed (Fig. 2). Bound PU and SD showed an increase throughout senescence, whereas bound SM decreased. Kinetin slowed the increase of thylakoidbound PU and SD and kept the bound SM almost at the initial level (at day 0) (Fig. 2). This data suggests a different role of PU/SD and SM in the process. Developmental cell death (DCD) of tobacco flowers (Serafini-Fracassini et al., 2002) as well as senescence in Rosa bourboniana (Shweta \& Nagar, 2003) can be delayed by an exogenous supply of PAs, with SM being particularly efficient. In general, SM is known as the most abundant PA conjugated to isolated LHCPII (Della Mea et al., 2004) and the reaction center of photosystemII (Kotzabasis et al., 1993).

The decrease in bound SM during thylakoid degradation could be related to the breakdown of chloroplasts, degradation of LHCPII as well as other proteins of the chlorophyll $a / b$ antenna complexes,

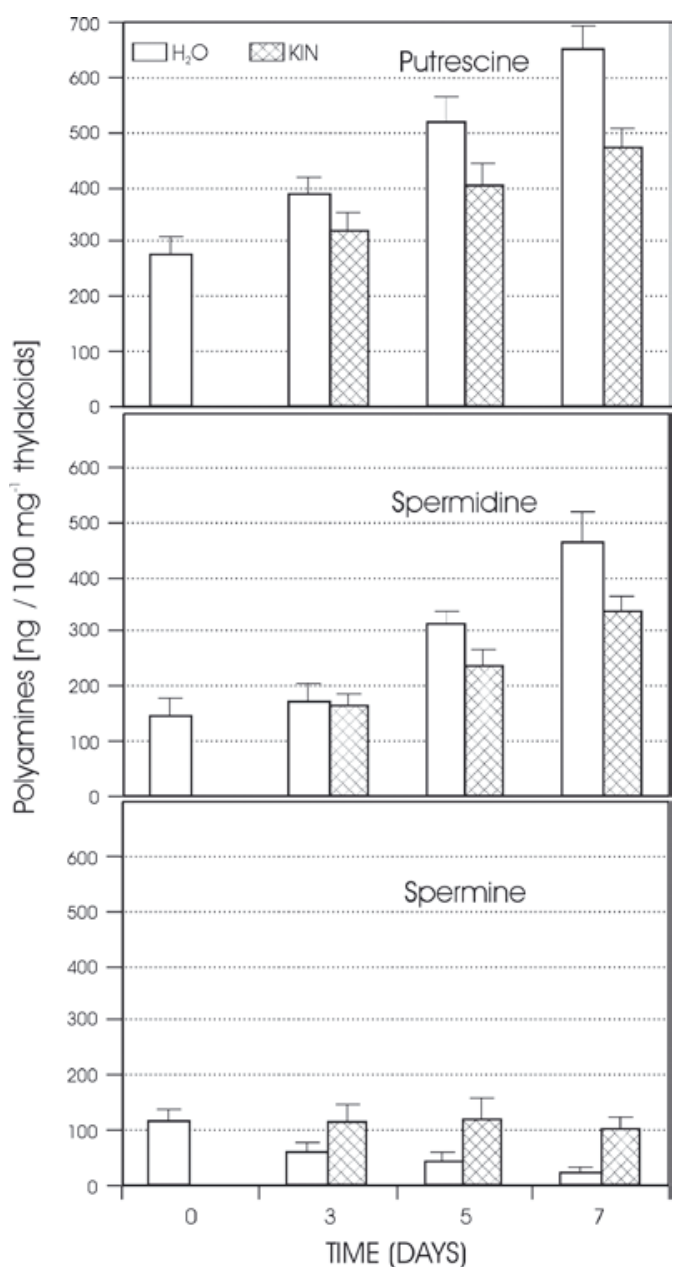

Figure 2. Level of polyamines: PU, SD and SM bound to thylakoids of barley leaves.

Leaves were treated as described for Fig. 1. Data represent means \pm S.E. of three replicates. Differences between control and kinetin samples are significant at days 3, 5 and 7 for PU and SM and at 5 and 7 for SD at $P<0.05$.

whereas the increase in bound PU and SD appears to be related to dark-induced senescence and might be partly related to the increase in TGase activity during this process (Fig. 4), as is discussed later.

Immunodetection of TGases in the thylakoid fraction of senescing barley leaves revealed bands at 33, 58 and $78 \mathrm{kDa}$ (Fig. 3). Evidence from other studies has shown that more than one protein with a TGase activity could be present in the same tissue, cell or different compartments of the same cell or even within the same organelle (for review see: Serafini-Fracassini \& Del Duca, 2008). A 35-38 kDa form seems to be found exclusively in plastids, and is also reported in bacteria (Makarova et al., 1999), from which plastids are phylogenetically derived. The $58-\mathrm{kDa}$ TGase is widespread in chloroplasts of higher plants and algae and it most likely acts to stabilize the photosynthetic complexes (Serafini-Fracassini \& Del Duca, 2008). With respect to the West- 


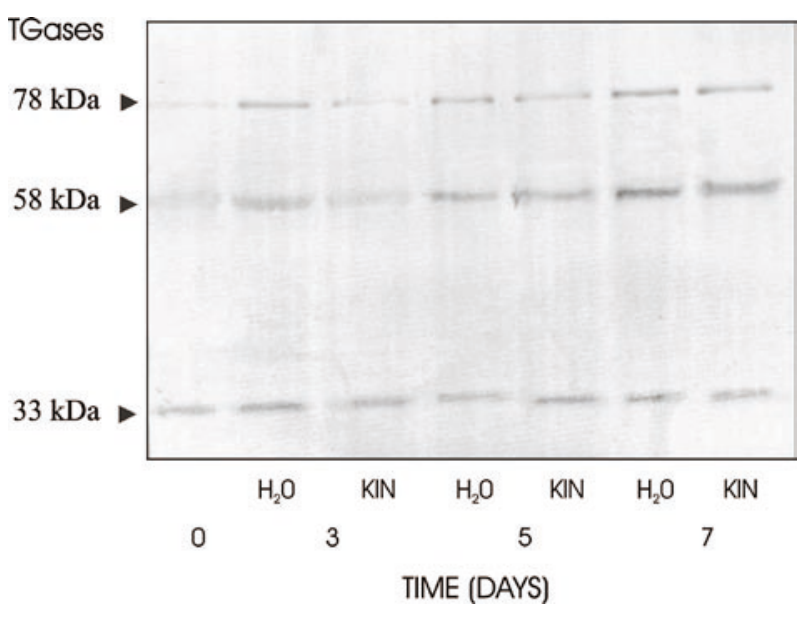

Figure 3. Immunodetection of barley thylakoid TGases. Proteins were isolated from thylakoids of barley leaves. Leaves were treated as described for Fig. 1. Membrane proteins $(10 \mu \mathrm{g})$ were loaded onto a $12 \%$ SDS/polyacrylamide gel and electrophoresed. ExtrAvidin Peroxidase immunostaining was performed with antibodies raised against TGases. Primary antibody dilution: 1:5000.

ern blotting result (Fig. 3), the 78-kDa band could be similar to the 77-kDa band cited as a native form of a mammalian TGase, which is cleaved into one fragment containing the active site (about $58 \mathrm{kDa}$ ) and another inactive fragment around $30 \mathrm{kDa}$ (Griffin et al., 2002). During senescence the intensity of all bands increased (Fig. 3). The most intensive protein band was that of $58 \mathrm{kDa}$. In control leaves at day 0 the levels of 58 and $78 \mathrm{kDa}$ TGases were very low and increased significantly throughout the process (from day 3 to 7). Kinetin down-regulated the accumulation of 58 and $78 \mathrm{kDa}$ bands. At day 3 the level of TGases in kinetin-treated leaves was similar to the level in control leaves at day 0 .

The colorimetric TGase activity assay was performed in the presence of $N^{\prime}, N^{\prime}$,-dimethylcasein (Fig. 4). As the exogenous substrate is present in a constant amount throughout the different stages of senescence, the observed differences in TGase activity are expected to reflect the changes of the enzyme level. In control leaves the TGase activity increased continuously through senescence and at days 3, 5 and 7 it was about 3, 4 and 6 times higher, respectively than at day 0 . Kinetin slowed the increase in the TGase activity about two-fold (Fig. 4).

The data from Figs. 3 and 4 shows that there is a positive correlation between the TGase level and enzymatic activity. The level and activity increased throughout the senescence process.

In tobacco flowers TGases are also involved in senescence in a similar way to their involvement in animal apoptosis (Serafini-Fracassini et al., 2002; Della Mea et al., 2007b). Our colorimetric assay in barley leaves (Fig. 4) showed changes of TGase ac-

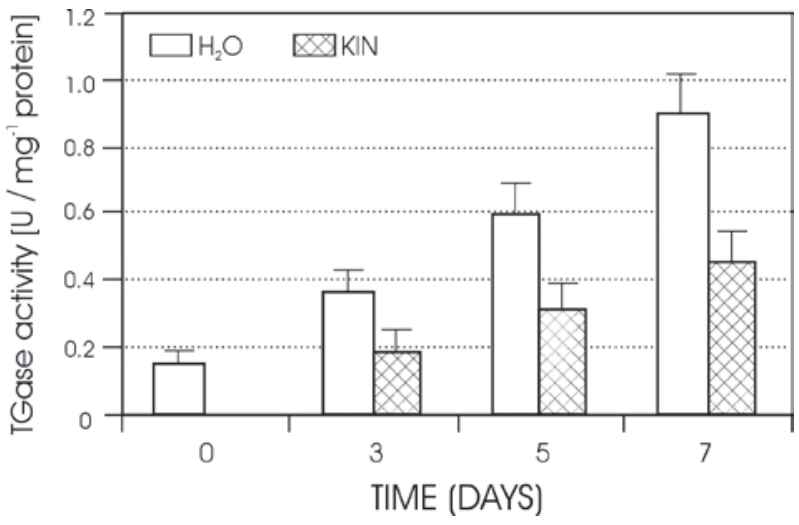

Figure 4. Specific TGase activity in barley leaf thylakoid fraction.

Leaves were treated as described for Fig. 1. The TGase activity was evaluated as biotin-cadaverine binding to $N^{\prime}, N^{\prime}$,-dimethylcasein. Data represent means \pm S.E. of three replicates. Differences between control and kinetin samples are significant at days 3, 5 and 7 at $P<0.05$.

tivity similar to those in tobacco flowers, where the activity increased in the terminal stage of developmental cell death (DCD). In isolated chloroplasts of tobacco petals, exogenously supplied $\left[{ }^{3} \mathrm{H}\right] \mathrm{PU}$ was metabolised in order to produce a definite mono-PU/ bis-SD ratio (Serafini-Fracassini et al., 2002). TGase mono- and bis-derivatives can play different roles, e.g. mono-PAs are substrates of PA oxidases (Serafini-Fracassini et al., 2002). Formation of hydrogen peroxide and cytotoxic products via PA catabolism is considered as one of the possible mechanisms of PAs involvement in PCD (Yoda et al., 2003).

Furthermore, Novakoudis and her colleagues (2007) reported on a mechanism that regulates the plasticity and adaptation status of the photosynthetic apparatus and found that modification of the structure of LHCII and CPs by any of the PAs can drastically affect their conformation - either stabilising them or exposing them to protease activity.

Besides, enzymes such as proteases, nucleases, enzymes involved in lipid and carbohydrate metabolism and in nitrogen mobilisation are drastically activated during senescence (Buchanan-Wollaston, 1997). During senescence TGases might alter these enzymes' function by "cationisation" and/or crosslinking with PAs, with obvious structural consequences.

The results presented in this communication indicate that during chloroplast degradation the formation of covalent adducts of PAs by a TGase-catalysed reaction took place and that this might be one of the mechanisms of PAs action in senescence. The kinetin-mediated preservation of low TGase levels and activity throughout leaf senescence could rep- 
resent an important component of the mechanism of hormone action in retardation of senescence.

The role of bound PAs throughout the process is discussed and further biochemical and functional studies, including loss of function of the corresponding genes, which are in progress, are needed to fully reveal the overall function of these forms of PAs in senescing chloroplasts.

\section{Acknowledgements}

The authors are very indebted to Agnieszka Kazikowska for the preparation of the figures.

\section{REFERENCES}

Bradford MM (1976) A rapid and sensitive method for quantitation of microgram quantities of protein utilizing the principle of protein-dye-binding. Anal Biochem 72: 248-254.

Buchanan-Wollaston V (1997) The molecular biology of leaf senescence. J Exp Bot 48: 181-199.

Del Duca S, Tidu V, Bassi R, Esposito C, Serafini-Fracassini D (1994) Identification of chlorophyl-a/b proteins as substrates of transglutaminase activity in isolated chloroplasts of Helianthus tuberosus L. Planta 193: 283-289.

Della Mea M, Di Sandro A, Dondini L, Del Duca S, Vantini F, Bergamini C, Bassi R, Serafini-Fracassini D (2004) A Zea mays 39-kDa thylakoid transglutaminase catalyses the modification by polyamines of light-harvestnig complex II in light-dependent way. Planta 219: 754-764.

Della Mea M, Serafini-Fraccasini D, Del Duca S (2007a) Programmed cell death: similarities and differences in animals and plants. A flower paradigm. Amino Acids 33: 395-404.

Della Mea M, De Filipis F, Genovesi V, Serafini-Fracassini D, Del Duca S (2007b) The acropetal wave of developmental cell death (DCD) of Nicotiana tabacum corolla is preceded by activation of transglutaminase in different cell compartments. Plant Physiol 144: 1211-1222.

Dondini L, Del Duca S, Dall Agata L, Bassi R, Gastaldelli M, Della Mea M, Di Sandro A, Claparlos I, SerafiniFracassini D (2003) Suborganellar localisation and effect on light Helianthus tuberosus chloroplast transglutaminase and their substrates. Planta 217: 84-95.

Griffin M, Verderio E (2000) Tissue transglutaminase in cell death. In Programmed cell death in animal and plants. Bryant JA, Hughes SG, Garland IM, eds, pp 223-241. Oxford BIOS Scient Publishers Ltd.

Griffin M, Casadio R, Bergamini CM (2002) Transglutaminases: Nature`s biological glues. Biochem J 368: 377396.

Hilditch P (1986) Immunological quantitation of the chlorophyll $a / b$ binding protein in senescing leaves of Festuca pratensis. Plant Sci 45: 95-99.

Jackowski G (1996) Senescence-related changes in the subcomplex arrangement of the major light-harvesting chlorophyll $a / b$-protein complex of photosystem II (LHCII) as influenced by cytokinin. Z Naturforschung 51: 464-472.

Kotzabasis K, Fotinou C, Roubelakis-Angelakis KA, Ghanotakis D (1993) Polyamines in the photosynthetic apparatus. Photosynth Res 38: 83-88.
Kuehn GD, Phillips GC (2005) Role of polyamines in apoptosis and other recent advances in plant polyamines. Critical Rev Plant Sci 3: 145-155.

Kusano T, Berberich T, Tateda C, Takahashi Y (2008) Polyamines: essential factors for growth and survival. Planta 228: 367-381.

Laemmli UK (1970) Cleavage of structural proteins during the assembly of the head of bacteriophage T4. Nature 227: 680-685.

Legocka J, Zajchert I (1999) Role of spermidine in the stabilization af the apoprotein of the light-harvesting chlorophyll $a / b$-protein complex of photosystem II during leaf senescence process. Acta Physiol Plant 21: 127-132.

Lilley G, Skill J, Griffin M, Bonner P (1998) Detection of $\mathrm{Ca}^{2+}$-dependent transglutaminase activity in root and leaf tissue of monocotyledoneus and dicotyledoneous plants. Plant Physiol 117: 1115-1123.

Lorand L, Graham R (2003) Transglutaminases: crosslinking enzymes with pleiotropic functions. Nature Rev Mol Cell Biol 4: 140-156.

Makarova KS, Aravind L, Koonin EV (1999) A superfamily of archaeal, bacterial, and eukaryotic proteins homologous to animal transglutaminases. Protein Sci 8: 17141719.

Navakoudis E, Vrentzou K, Kotzabasis K (2007) A polyamine- and LHCII protease activity-based mechanism regulates the plasticity and adaptation status of the photosynthetic apparatus. Biochim Biophys Acta 1767: 261-271.

Quirino B, Noh YS, Himelblau E, Amasino R (2000) Molecular aspects of leaf senescence. Trends Plant Sci 5: 278-282.

Seiler N, Raul F (2005) Polyamines and apoptosis. J Cell Mol Med 9: 623-642.

Serafini-Fracassini D, Del Duca S (2008) Transglutaminases: widespread cross-linking enzymes in plants. Annal Bot 102: 145-152.

Serafini-Fracassini D, Del Duca S, Monti F, Poli F, Sacchetti G, Bregoli AM, Biondi S, Della Mea M (2002) Transglutaminase activity duing senescence and programmed cell death in the corolla of tobacco (Nicotiana tabacum) flowers. Cell Death Differ 9: 309-321.

Shweta S, Nagar PK (2003) The effect of polyamines on leaf senescence in two diverse rose species. Plant Growth Regul 39: 155-160.

Smith TA, Best GR (1977) Polyamines in barley seedlings. Phytochem 16: 841-843.

Sobieszczuk-Nowicka E, Di Sandro A, Del Duca S, Serafini-Fracassini D, Legocka J (2007) Plastid-membrane-associated polyamines and thylakoid transglutaminases during etioplast- to chloroplast transformation stimulated by kinetin. Physiol Plant 130: 590-600.

Sobieszczuk-Nowicka E, Krzesłowska M, Legocka J (2008) Transglutaminases and their substrates in kinetin-stimulated etioplast-to-chloroplast transformation in $\mathrm{cu}$ cumber cotyledons. Protoplasma 233: 187-194.

Szweykowska A, Schneider J (1994) Cytokinins and the photosynthetic apparatus in plants. In Agro's Annual Review of Plant Physiology (Basic \&Applied) Purohit SS, Sahu MP, eds, vol 1, pp 123-145. Agro Botanical Publisher, Bikaner, India.

Yoda H, Yamaguchi Y, Sano H (2003) Induction of hypersensitive cell death by hydrogen peroxide produced through polyamine degradation in tobacco plants. Plant Physiol 132: 1973-1981.

Żelisko A, Jackowski G (2004) Sensecence-dependent degradation of Lhcb3 is mediated by a thylakoid membrane-bound protease. J Plant Physiol 161: 1157-1170. 